\title{
Posterior Wall of the Nasopharynx
}

National Cancer Institute

\section{Source}

National Cancer Institute. Posterior Wall of the Nasopharynx. NCI Thesaurus. Code C12243.

The dorsal portion of the nasopharyng eal cavity that contains the pharyngeal tonsil. 